\title{
Review of the Portfolio Theory Application
}

\author{
Yanyu Xiao ${ }^{1, *}$
}

\author{
${ }^{1}$ Northeastern University at Qinhuangdao \\ *Corresponding author. Email: guanghua.ren@gecacademy.cn
}

\begin{abstract}
Portfolio investment is the core of all kinds of investment activities in the financial market, is an investment decision under uncertain conditions, is an important branch of the economic field. The portfolio is a common way to avoid risk. A portfolio is generally considered to be a combination of bank deposits, bonds, stocks, real estate, precious metals and other investments. In the securities market, that is, even one investment direction has the portfolio problem, and some people call the portfolio of the same investment direction "diversified investment". Therefore, it is very important to study and summarize and analysed the application of portfolio theory. This paper studies the portfolio theory by means of a literature review. Through concept, application model and industry analysis, it is reviewed in detail. The results show that the q-factor model and Fama-French 5-factor model are seldom used in securities, stocks, real estate and other industries. The current research on the CAPM model is more abundant than the previous two models, but there is less research on changing abnormal economic forms. On the one hand, the conclusion of this paper summarizes the investment theory. On the other hand, it lays a theoretical foundation for investment practice.
\end{abstract}

Keywords: investment, portfolio model, industry review

\section{INTRODUCTION}

In today's market, people can freely choose and invest according to their own strength and judgment. The initial investment means that investors use the money to invest in a specific project (commercial project, engineering project, real estate project, etc.) or directly build a factory enterprise. This type of investment is the initial typical direct investment. It is both venture capital and industrial investment. Nowadays, the way of investment has changed. Through capital operation, purchase of equity, and equity replacement, the goal of controlling projects and enterprises are realized. In addition, with the emergence and development of the capital market, a large number of financial investment products have appeared. For the general public, it is to invest money in securities products and financial products.

\section{MAIN BODY}

\subsection{Investment}

Investment refers to the process by which countries or enterprises and individuals sign agreements with each other for specific purposes to promote social development, achieve mutual benefit, and transfer funds
[1]. It is also the economic behavior of a specific economic entity to obtain income or capital appreciation in the foreseeable future, in a certain period to invest a sufficient amount of money or physical currency equivalents in a certain field. It can be divided into a physical investment, capital investment and securities investment [2]. The former uses currency to invest in the enterprise to obtain a certain profit through production and business activities. The latter uses currency to purchase stocks and corporate bonds issued by the enterprise to indirectly participate in the enterprise's profit distribution.

There are many types of investment, such as real estate, bonds, stocks, precious metals, funds, short-term bank financial products, trusts, private loans and other forms. As investment continues to evolve and develop, more and more investment models are used in economic investment. For example, the CAPM, q-factor, and Fama-French 5-factor models are three very classic investment models. 


\subsection{Model}

\subsubsection{CAPM model}

The Capital Asset Pricing Model (CAPM) describes the relationship between systematic risk and expected return for assets, particularly stocks. CAPM is widely used throughout finance for pricing risky securities and generating expected returns for assets given the risk of those assets and cost of capital [3]. The CAPM model's primary purpose is to explore how much remuneration investors should receive to compensate for a particular degree of risk. The development of capital and financial markets depends on the development of the CAPM model, which is widely used in micro and macro fields such as investment decision-making and theoretical analysis.

Assumptions:

1. All investors can obtain sufficient market information in time for free.

2. All investors are rational.

3. The more wealth the investor has, the better.

4. The probability of the yield of securities obeys normal distribution.

5. All investors have the same earnings expectations.

6. The transaction cost is zero.

Formula:

\subsection{2 q-factor model}

The Q-factor model includes four risk factors [4]. The first is the market factor, which encompasses both macroeconomic and overall market risk premiums. The second is the size factor that represents the market capitalization of a firm. The third factor is the investment factor. Investment means physical investment rather than a financial investment, such as building a factory or buying new equipment. The last factor is profitability. Earnings are the accounting profit ratio, which is equal to profit divided by book capital. To test the model efficiency, one needs to do a FamaMacbeth regression by regressing the cross-sectional return on the returns of the four factors. If the model is correct, the abnormal return (the intercept) should be statistically zero. But even zero does not prove that CAPM anomalies do not exist, nor does it mean that there is no room for quantitative investment. The fact that the abnormal rate of return is zero in the Q-factor model indicates that the different abnormal variables are just different combinations of investment and profit factors. That is to say, and the Q-factor model is very useful empirically. In today's financial markets, the Q factor model is widely used. For example, in recent years, several large investment managers, such as BlackRock and State Street, have made large factor investments through exchange-traded funds (ETFs).

\subsubsection{Fama-French 5-factor model}

As early as 1993, Fama and French have proposed a three-factor model, arguing that the excess returns of stocks can be jointly explained by market risk, market value risk, book value ratio risk [5]. Later, they found that in addition to the above risks, there are profit level risks and investment level risks that can also bring the excess returns of individual stocks. Therefore, based on the three-factor model, two factors are added: profitability and investment model and proposed the five-factor model.

Five-factor model:

$$
\begin{aligned}
& \left.R_{i t_{-}} R_{F t_{-}} a_{i i_{+}} b_{i(} R_{M t_{-}} R_{F t}\right)+S_{i} S M B_{t_{+}} h_{i} H M L_{t_{+}} r_{i} R M W_{t} \\
& { }_{+} c_{i} C M A_{t_{+}} e_{i t}
\end{aligned}
$$

Where is the expected portfolio return, Rft is the risk-free yield, Rmt is the expected return for the market portfolio, and (Rmt-Rft) is the risk premium factor.SMB is a scale factor, HML is the book market value ratio factor, RMW is the difference in return on a high / lowprofit equity portfolio. At the same time, CMA is the difference in return for low/high reinvestment ratios. These two items respectively describe the profit level risk and the investment level risk (note that the investment level here is not the investment level of the secondary market but can be colloquially interpreted as the ability of enterprises to expand reproduction). Similar to the three-factor approach, the parameter estimation method is still done by multivariate linear regression. Here is an unexplained excess gain in the five-factor model.

\subsection{Industry Overview}

\subsubsection{Application of CAPM model in different industries}

The CAPM model pioneered the quantitative modeling of financial asset return risks. In different industries, the CAPM model is also widely used. For example, in the stock market, Wang selected the stock market data of Shanghai, China, after the 2008 financial crisis and used definition and interface regression to test the CAPM model's ability to interpret the market. He believed that the CAPM model could be used to link individual stock returns with market returns. It also provides an important indicator $\beta$ to measure with the degree of stock volatility. The conclusion is the same as most scholars. The CAPM model is not valid in the 
Chinese market [6]. Based on the CAPM model, wu \& Jia analysed 50 stocks in the 50 sectors of the Shanghai Stock Exchange as sample data and used time series analysis and cross-sectional least squares regression methods to test whether systemic risks have an impact on individual stocks. In the end, it is concluded that non-systematic risk has a greater impact on stock returns, and the relationship between systemic risk and investment yield does not conform to the CAPM model and demonstrates that the establishment of investment portfolios can achieve the effect of dispersing nonsystematic risks [7]. In the securities market, Gao compares the assumptions of the CAPM model with my country's securities market. Firstly, he analyzes the reasons why the application of CAPM in my country's securities market is not ideal; secondly, he proposes two aspects: the revision of the model and the improvement of the securities market. The method adapts to theory and practice; finally, this paper summarizes the empirical research and improvement direction in my country's securities market [8]. In the real estate market, Wang used the statistical software Eviews to perform linear regression on the collected stock data based on relevant feasibility tests on the stock data of listed real estate companies in my country and obtained the existence of the relationship between the stock return rate of the real estate company and the market return rate. A certain degree of positive linear correlation and the $\beta$ value can better explain the changes in stock returns to a certain extent [9]. Chen selected 80 stocks in the Shanghai and Shenzhen A-share real estate sector from 2015 to 2017 as the research objects and used the Fama \& MacBeth (1973) three-stage regression method to test the applicability of the CAPMP model. Finally, it was confirmed that the real estate sector stocks have high systemic risks. , The market fluctuates greatly; secondly, the real estate stocks return rate, and the beta coefficient is basically linearly related, but the beta coefficient is negative, which does not conform to the laws of the capital market; finally, real estate stocks not only fluctuate greatly in the beta value of individual stocks but also the investment portfolio The $\beta$ coefficient is also extremely unstable. Therefore, the CAPM model is not applicable in China's real estate stock market [10].

In addition, many scholars have entered into more in-depth research on the CAPM model in multiple industries such as the medical industry, industry, and tourism. As a result, it can be seen that the CAPM model is widely used.

\subsubsection{Application of q-factor model in different industries}

For the abnormal phenomena in the stock market, Fang and Meng compare the pricing power of the qfactor model and the Fama\&French model by examining the model's ability to explain market anomalies. The empirical research results show that the q-factor model and the Fama\&French 5-factor model have their own strengths in interpreting market anomalies. However, in general, the q-factor model's ability to explain certain market anomalies has improved compared with the Fama\&French 3-factor model and the Fama\&French 5-factor model: the effect of the beta value, the effect of comprehensive stock issuance, and the effect of accrued profits. , Momentum effect, B/M effect and investment effect are stronger than the Fama\&French 3-factor model; the q-factor model is in the four market anomalies of volatility effect, accrued profit effect, B/M effect and investment effect. As a result, the performance is better than Fama\&French 5-factor model [11]. Regarding the longterm risks of the market, $\mathrm{Wu}$ incorporates productivity risks into the investment-based q-factor model. And believes that productivity risk factors largely summarize the cross-sectional head portfolio returns, in which the volatility over time plays an important role. Compared with the Fama-French factor model, Carhart (1997) four-factor model, and Hou, Mo, Xue \& Zhang (2020) five-factor model, a q-factor model driven by productivity risk explains about 90\%; 25-size B/M portfolios and 160 investment portfolios have a return change of approximately $75 \%$, which is similar to the Fama-French factor model. Therefore, the risk of productivity growth may be one of the potential forces driving investment-based factor models [12]. Regarding the average return on the market, Hou, Mo, Xue, and Zhang pointed out that when holding investments and expected profitability continues to increase, companies with high expectations of investment growth obtain lower investment growth than expected. The q-factor model and the expected growth factor show strong explanatory power in the cross section and are superior to the Fama \& French 6-factor model [13].

\subsubsection{Fama\&French 5-fator model}

From the CAPM model to the APT model to the Fama\&French three-factor model to the later Fama\&French five-factor model, the pricing model has gradually become perfect. In today's academia, the research on the Fama\&French 5-factor model has also become more and more thorough.

Regarding the Chinese stock market, Li, Yang, Feng, Jing took A-share listed companies from July 1994 to August 2015 as a sample, and examined the application of the five-factor model in different periods of China's stock market, and came to the following conclusions: scale, The book-to-market value ratio effect is significant. The profitability and investment style effects are still significant after adjustment by the Fama\&French 3-factor model, but there is no significant momentum or reversal effect; the Fama\&French 5- 
factor model has very strong explanatory power, which is stronger than CAPM, Fama\&French The 3-factor model and the Carhart four-factor model performed better; before the share reform, the market risk occupied a dominant position, and the profitability, investment style and momentum factors were "redundant". After the share reform, the risk premium of these three factors was significant; after the share reform, the Fama\&French The 5-factor model still has a significant reversal effect after adjustment; the difference between the actual rate of return and the expected rate of return after the share reform is closer to 0 , and the market tends to be more efficient [14]. Liu used the Fama\&French 5-factor model to perform regression to verify the model's applicability in my country's A-share market and the explanatory strength of various factors on excess returns. The following conclusions can be drawn through empirical testing: Fama\&French 5-factor model applies to my country's A-share market. The scale factor and the orthogonalized profit factor perform significantly, and they have a strong explanatory power for explaining the excess returns in my country's Ashare market. The value factor is not significant in my country's A-share market. Still, it is negatively related to the company's earnings with a low book-to-market value ratio. It positively correlates with the high bookto-market value ratio and the return rate of high-profit companies. The overall investment factor is not significant, but it has explanatory power for the excess returns of small-scale companies with high investment growth rates. And found that the Fama\&French 5-factor model is not suitable for various market segments in my country. In each stock industry, the scale factor is significant, indicating a significant scale effect in each industry in our country. The value factor is not very significant, but positively correlated with the excess return in several significant industries. Profit factors are positively significant in most industries, proving the positive correlation between profitability and stock returns. Investment factors are also positively significant in most industries, indicating that companies with lower investment levels will have higher excess returns [15].

In the securities market, Gao\&Zhang divides the test time period according to different markets and selects China Shanghai and Shenzhen stock portfolio; the results show that the return rate of the portfolio constructed by the Fama\&French 5-factor model and its robustness is affected by market sentiment, while the stable median Covariance matrix can reduce the volatility of portfolio returns. Still, the effect is not obvious during periods of high market sentiment [16].

In the trade circulation market, Liu tested the applicability of the Fama\&French 5-factor model in the stock analysis of listed companies in my country's trade circulation. The results show that the Fama\&French 5factor model is applicable in analysing the stocks of listed companies in my country's commercial and trade circulation. After adjusting the risk premium, the CMA factor is no longer redundant in the five-factor model by controlling the influence of other factors. It explains well the changes in the rate of return of the stocks of listed companies in trade circulation [17].

\section{CONCLUSION}

Through a summary of the previous literature, it is found that the CAPM model is no longer fully applicable in the current Chinese stocks, securities and other markets. However, until a complete pricing analysis model comes out, CAPM is still an important tool in the field of financial management. q-factor model and the Fama\&French 5-fator model.

Among the three models, the CAPM model is obviously more in-depth and extensive than the q-factor model and the Fama\&French 5-factor model, and the application and research in all walks of life are also more in-depth. The CAPM model has a solid mathematical foundation and is easy to implement under theoretical conditions. However, there are more obvious shortcomings in the real long-term application. For the q-factor model and the Fama\&French 5-factor model, the main research scope is still in the financial field. For other industries, such as medical and industrial industries, relatively little related literature needs to be studied.

Therefore, future researches on the q-factor model and Fama\&French 5-factor model can focus on exploring the application of financial industry other than stock industry and securities industry, or even the application of industry, medical industry and real estate industry. Research on the CAPM model can focus on exploring changes before and after COVID-19.

\section{REFERENCES}

[1] Capolupo, R. (2018). Finance, investment and growth: Evidence for Italy. Economic Notes: Review of Banking, Finance and Monetary Economics, 47(1), 145-186.

[2] Krasyuk, I. A., Kobeleva, A. A., Mikhailushkin, P. V., Terskaya, G. A., \& Chuvakhina, L. G. (2018). Economic interests focusing as a basis of the formation of investment policy. Espacios, 39(28), $518-531$

[3] Bao, T., Diks, C., \& Li, H. (2018). A generalized CAPM model with asymmetric power distributed errors with an application to portfolio construction. Economic Modelling, 68, 611-621.

[4] Ahmed, S., Bu, Z., \& Tsvetanov, D. (2019). Best of the best: a comparison of factor models. Journal of Financial and Quantitative Analysis, 54(4), 17131758. 
[5] Smith, M. M., Sherry, S. B., Vidovic, V., Saklofske, D. H., Stoeber, J., \& Benoit, A. (2019). Perfectionism and the five-factor model of personality: A meta-analytic review. Personality and Social Psychology Review, 23(4), 367-390.

[6] Wang Xiaohan. (2017).An Empirical Study of the Effectiveness of the Capm Model in the Chinese Stock Market.Yin Mountain Journal (Natural Science Edition), 31 (004), P.101-103,110.

[7] Wu Yancheng, Judzheng.(2015).___ takes the Shanghai Stock market as an example. Enterprise Technology Development (34), 99-101.

[8] Gao Miaoyong.(2016).The Empirical Research and Improvement Direction of the Capm Model in the Chinese Securities Market.The Chinese market (50).

[9] Wang Guan.(2019).Effectiveness test of the Capm model in the real estate industry. Industry and Technology Forum, 018 (017), 139-140.

[10] Chen Mengyuan.(2019).Effectiveness test of Capm model: China's real estate stock market. Financial Economy, No.516(18), 71-73.

[11] Fang Yi, Meng Jixian, \& Qu Junshan. (2019). Comparative study on a multifactorial pricing model based on market vision. Quantitative Economy Research, 000 (001), P.82-96.

[12] Wu, Z. (2021). A Long-Run Productivity Risks Driving q-Factor Model.

[13] Hou, K., Mo, H., Xue, C., \& Zhang, L. (2021). An augmented q-factor model with expected growth. Review of Finance, 25(1), 1-41.

[14] Li Zhibin, Yang Guangyi, Feng Yongchang, \& Jing Liang.(2017).Empirical test of the Fama-french five-factor model in the Chinese stock market. Financial Research, 000 (006), 191-206.

[15] Liu Xinyue.(2019).Empirical analysis of the applicability of Fama-French five-factor model in China's A-share market and various industry sectors.(Doctoral dissertation, Capital University of Economics and Trade).

[16] Gao Ke, \& Zhang Linzi.(2019).Investor sentiment, the fama-french five-factor model with portfolio earnings. Institutional Economics Research (03), 245-257.

[17] Liu Lili, \& Liu Yu.(2020).Applability test of Famafrench five-factor model in stock analysis of listed enterprises. Business Age, 000 (002), 172-174. 